\title{
ЗАКОНОДАТЕЛЬНЫЕ АКТЫ АЗЕРБАЙДЖАНСКОЙ РЕСПУБЛИКИ В РЕГУЛИРОВАНИИ ОТНОШЕНИЙ ПО ДОГОВОРУ МЕЖДУНАРОДНОЙ ВОЗДУШНОЙ ПЕРЕВОЗКИ ПАССАЖИРА И БАГАЖА
}

\author{
МАНИЗАДЕ Джамиль Фахраддин оглу - диссертант Национальной \\ Академии Авиации Азербайджана \\ УДК 341 \\ DOI 10.32782/EP.2021.28
}

Автор считает иелесообразньлм, изменить статью 13 Закона Азербайджанской Республики «О транспорте» и указать в этой статье предложение следующего содержания: «Пассажирь могут до начала перевозки сдать билет и получить обратно уплаченную сумму у осуществляющего перевозку транспортного предприятия (перевозчика), если этот билет не приобретен по специальному тарифу, правилами применения которого не предусмотрен возврат сумм».

Ключевъе слова - Азербайджанская Республика, конституиия, кодекс, статья, договор.

Наряду с международными соглашениями, участником которых является Азербайджанская Республика, другие акты, включенные в законодательную систему Азербайджанской Республики, имеют важное значение для регулирования международных перевозок пассажиров и багажа воздушным путем. Причина кроется в том, что международные конвенции и двусторонние соглашения не в состоянии регулировать все детали взаимоотношений перевозки пассажиров и багажа. Другими словами, иногда возникают пробелы в выполнении международных конвенций и двусторонних соглашений. В таких случаях пробел может быть восполнен с помощью других нормативных правовых актов, включенных в законодательную систему Азербайджанской Республики, то есть с помощью национального законодательства.

Как правильно отмечает, М.Н. Марченко, «важное значение при изучении права того или иного государства и общества, рассмотрение его не только самого по себе (понятие, признаки, бормы и т.д.) или в системе других сочцальньгх норм, но и исследование национального (внутригосударственного) права в сравнении с международнъим» (1, с. 467).

Считаем необходимым констатировать, что международное право и внутреннее (национальное) право - это правовые системы, которые действуют независимо, но взаимосвязаны и взаимодействуют друг с другом. Конституция Азербайджанской Республики не обошла вниманием вопрос о нормативном ранге международных договоров, включенных в национальное законодательство. Решение этого вопроса в статье 151 Основного Закона отражено следующим образом: «При возникновении противоречия между нормативно-правовъми актами входящими в систему законодательства Азербайджанской Республики (исключая Конституцию Азербайджанской Республики и акть, принятьие путем реберендума), и межгосударственными договорами, стороной которьх является Азербайджанская Республика, применяются международнъе договорь»». На первый взгляд кажется, что в этой статье Конституция закрепила верховенство международного права. Однако на самом деле статья 151 играет роль разрешения возможных противоречий между положениями международного договора и нормативными правовыми актами Азербайджанской Республики. Как видно, данная статья предусматривает только межгосударственные договоры, сторонником которых является Азербайджанская Республика. 
Что касается юридической силы межправительственных соглашений, то из подпункта 6 пункта III статьи 130 Конституции следует, что в нормативной иерархии они находятся ниже Конституции и законов Азербайджанской Республики.

Отметим, что в современном мире существует более 200 государств и по количеству государств столько же национальных правовых систем. Правовая система означает внутреннюю структуру, выражающуюся в единстве и гармонизации правовых норм, действующих на территории государства, а также в разделении права на относительно самостоятельные части.

В научной литературе отмечается, что «правовая семья - это несколько родственньх национальнъих правовых систем, которье характеризуются сходством некоторьих важньх признаков (пути формирования и развития; общность источников, принципов регулирования, отраслевой структурьі; унибицированность юридической терминологии, понятийного аппарата; взаимозаимствование основньх институтов $и$ правовъхх доктрин» (2, с. 88).

Национальное законодательство регулирует международные авиаперевозки пассажиров и багажа, в первую очередь, с помощью норм материального характера, имеющих прямую силу. Эти нормы специально разработаны для регулирования отношений транспортных перевозок с иностранными элементами. Кроме того, национальное законодательство может регулировать международную перевозку пассажиров и багажа воздушным транспортом с помощью своих собственных коллизионных норм (под коллизионными нормами подразумеваются нормы права, регулирующие столкновение между гражданскими законами разных государств в случае возникновения международных гражданских отношений).

Таким образом, коллизионная норма, предусмотренная национальным законодательством, гласит о том, законодательство какой страны должно применяться к перевозке посторонних элементов, т.е. происходит выбор законодательства, которое будет применяться через коллизионную норму. Коллизионная норма определяет формулу конфликта (коллизионный принцип «lex voluntatis» - автономия воли) как «свободу воли сторон» для регулирования международного договора по воздушной перевозке пассажиров и багажа. Согласно этой формуле, стороны, участвующие в транспортных отношениях с иностранными элементами, могут выбирать законодательство того или иного государства для регулирования этих отношений по договоренности. Например, в статье 24, которая называется «Выбор права по соглашению участников договора» Закона Азербайджанской Республики «О международном частном праве», состоящего из 30-и статей, говорится: «Установление в связи с договором прав и обязанностей сторон, толкование, исполнение, неисполнение, прекращение договора, результать неисполнения его в необходимом порядке и недействительности, а также предусмотреннъе в требовании льготь и перечисление долга регулируются по соглашению сторон правом избранной странъ.

Сторонъи договора могут избрать право, подлежащее применению как к договору в чзелом, так и котдельным его частям.

Сторонъ могут избрать подлежащее применению право в любое время, в том иисле во время подписания договора или после этого. Сторонъ, кроме того могут в любое время прийти к соглашению об изменении права, применяемого в связи с договором.

Избрание в связи с договором права, способствующего неприменению императивньх норм странъ, недействительно». Такой принцип коллизии известен в законодательстве большинства стран мира.

Ряд национальных нормативных правовых актов Азербайджанской Республики - Закон Азербайджанской Республики «О транспорте», Закон Азербайджанской Республики «Об авиации», «Дисциплинарный устав на воздушном транспорте и его предприятиях специального обслуживания» утвержденным постановлением Кабинета Министров Азербайджанской Республики от 18 января 2002 года под номером 9, «Форма договора об обязательном страховании пассажиров» утвержденным постановлением Кабинета Министров Азербайджанской Республики от 27 сентября 2003 года под номером 127 (Этот документ утратил силу в соответствии с Постановлением Кабинета Министров 
Азербайджанской Республики от 19 декабря 2011 года под номером 204), «Правила выдачи сертификата эксплуатанта и признания аналогичных документов, выданных в других государствах, и требования к сертификатам эксплуатанта для различных категорий воздушных сообщений с целью обеспечения безопасности воздушного транспорта» утвержденным постановлением Кабинета Министров Азербайджанской Республики от 31 мая 2007 года под номером 87, «Порядок оформления договоров и составления документов по воздушным перевозкам согласно договорам, стороной в которых выступает Азербайджанская Республика, и законодательству» утвержденным постановлением Кабинета Министров Азербайджанской Республики от 11 июня 2007 года под номером 94, «Порядок предоставления информации об авиационной катастрофе или инциденте» утвержденным постановлением Кабинета Министров Азербайджанской Республики от 19 сентября 2008 года под номером 219, Закон Азербайджанской Республики «Об обязательном страховании» от 24 июня 2011 года и другие отражают нормы, касающиеся перевозки пассажиров и багажа, включая международные воздушные перевозки пассажиров и багажа.

Согласно законодательству, транспорт в Азербайджанской Республике, в том числе воздушный, находится в государственной, частной и муниципальной собственности. $\mathrm{B}$ соответствии со статьей 3 Закона $\mathrm{AP} « \mathrm{O}$ транспорте» «все владельиљ транспорта обладают равньми правами и одинаково зашищаются Законом». Әто означает, что международные воздушные перевозки пассажиров и багажа могут осуществляться находящимися в государственной, частной и муниципальной собственности самолетами. Однако, находящихся в муниципальной собственности самолетов в Азербайджанской Республике пока нет.

Согласно статье 9 Закона $\mathrm{AP} « \mathrm{O}$ транспорте» «осуществление перевозок пассажиров $и$ багажа проводится на основании соответствуюших договоров, заключенньх в соответствии $c$ законодательством. Условия перевозок и транспортно-экспедиционного обслуживания, а также материальная ответственность сторон определяются на основании заключеннъх ими догово- ров, если законодательством не предусмотрень другие случаи».

«Плата за перевозку пассажира и багажа устанавливается соглашением, если законодательством не предусмотренъ другие случаи. Спорьи, связаннье с внесением плать за перевозку, регулируются в соответствии с законодательством и договором по перевозке» (статья 11 Закона $\mathrm{AP}$ «О транспорте»).

«Перевозчик груза должен доставить пассажира и багаж в пункт назначения в срок, установленнълми нормативно-правовълм актами и договорами по правилам перевозок» (статья 12 Закона АР «О транспорте»).

На основании статьи 13 Закона AP «O транспорте» авиапассажиры могут пользоваться следующими основными правами:

- «приобретать билет по любому маршруту открыттому для авиаперевозок;

- бътть обеспеченными местом согласно приобретенному билету;

- бесплатно или на других условиях провозить детей в пределах возраста, установленного соответствуюшими нормативно-правовълм актами;

- бесплатно провозить с собой ручную кладь в пределах установленных норм; согласно тарифу сдавать для перевозки багаж;

- получать компенсацию за завершение перевозок позже указанного времени без уважительной причинь;;

- до начала перевозки сдать билет и получить обратно уплаченную сумму у осуществляющего авиаперевозку».

«Перевозчик, отказавшийся продолжать перевозку, должен за свой счет обеспечить доставку пассажира в пункт назначения или возместить пассажиру весь ущерб, причиненнъий в результате нарушения договора».

Несмотря на то, что согласно статье 13 Закона AP «О транспорте», пассажиры могут до начала перевозки сдать билет и получить обратно уплаченную сумму у осуществляющего перевозку транспортного предприятия (перевозчика), в пункте 20.3.1 «Правила перевозок пассажиров, багажа и груза» Закрытого Акционерного Общества «Азербайджан Хава Йоллары», говорится: «За билет, приобретенный по специальному тарифу, правилами применения которого не предусмотрен возврат сумм, авиакомпания име- 
ет право отказать в возврате сумм за такой билет. Пассажир должен быть проинформирован Авиакомпанией (ее Агентом) об этом во время бронирования, и в билете должна быть сделана соответствующая отметка». По сравнению с Правилами, Закон обладает высшей силой. Однако на практике применятся пункт. 20.3.1 «Правила перевозок пассажиров, багажа и груза» Закрытого Акционерного Общества «Азербайджан Хава Йоллары». Аналогичный порядок о не возврате сумм за приобретенный по специальному тарифу билет, также предусмотрен в правилах большинства авиакомпаний, в том числе Аэрофлоте, Турецких авиалиниях и т.д. Считаем целесообразным, изменить статью 13 Закона АP «О транспорте» и указать в этой статье предложение следующего содержания: «Пассажиры могут до начала перевозки сдать билет и получить обратно уплаченную сумму у осуществляющего перевозку транспортного предприятия (перевозчика), если этот билет не приобретен по специальному тарифу, правилами применения которого не предусмотрен возврат сумм».

Авиапассажиры также могут пользоваться «правами застрахованного, установленнълми Законом Азербайджанской Республики «Об обязательном страховании» и Гражданским кодексом Азербайджанской Республики».

«Перевозчик должен обеспечить безопасность пассажира, создание условий для оказания ему необходимъгх услуг, своевременную перевозку и сохранность полученного багажа, груза» (пункт 1 статьи 16 Закона АР «О транспорте»).

В случае задержки рейсов по пассажирским перевозкам на 8 и более часов перевозчик должен за свой счет обеспечить пассажиров местом в гостинице и едой (пункт 5 статьи 16 Закона $\mathrm{AP}$ «О транспорте») и т.д.

В статьях 9.11, 43, 44, 46, 47, 49, 50 и т.д. в Закона AP «Об авиации» имеются нормы, посвященные международной перевозке пассажиров и багажа воздушным путем. Например, в статье 49 указанного Закона говорится: «Основания ответственности за ущерб, причиненньй в связи с эксплуатацией воздушнълх судов (ущерб, причиненнъий пассажирам, багажу или грузу в связи с воздушньлми перевозками, и ущерб, причиненныии при эксплуатации воздушного судна пассажирам или их имуществу, не пере- возимъим на борту воздушного судна) и порядок привлечения к ответственности устанавливаются международнъими договорами, к которьл присоединилась Азербайджанская Республика, и законодательством, с учетом положений XI главъl».

Обратимся к судебным актам, в которых нормы национального права применяются к спорам, возникающим при международной перевозке пассажиров и багажа воздушным транспортом. Истцы «A», «B», «C» и «D» подали иск против Азербайджанского представительства авиакомпании «Тюрк Хава Йоллары» в Хатаинский районный суд города Баку с просьбой о вынесении решения об удержании с ответчика 1.650 (одна тысяча шестьсот пятьдесят) долларов США за материальный ущерб, причиненный в результате неисполнения обязательств по договору перевозки пассажиров, а за причиненный моральный вред - удержании 70.000 (семьдесят тысяч) манатов. Истцы утверждали, что они воспользовались услугами авиакомпании «Тюрк Хава Йоллары» - на обратном пути в Баку из Турции, время их полета составляло 20 часов 55 минут, и что они прошли все необходимые процедуры в стамбульском аэропорту Ататюрк, зарегистрировали свои билеты и сдали багаж, на их загранпаспорта была поставлена печать о том, что они покидают страну, и подошли к воротам (GATE) ко времени в 20.30. Однако, когда они увидели, что двери закрыты, им сказали, что автобус уже забрал пассажиров и не вернется. Несмотря на то, что они предъявляли свои возражения, указывая на то, что подошли к воротам (GATE) на 25 минут раньше времени, указанного в билете, что их багаж был в багажнике самолета, что их можно было забрать за 15 минут до вылета и что двери были закрыты раньше, предъявленные протесты не дали положительного результата, в их авиабилетах и загранпаспортах был поставлен штамп «iptal» («отмена»), и им сообщили о необходимости еще раз приобрести авиабилет. Им пришлось пройти трехчасовую процедуру, затем снова получить новый билет для каждого из них, заплатить 1650 долларов и часами ждать, пока следующий самолет вылетит в Баку. По прибытии в Баку, несмотря на их пожелание забрать свой груз в багаже, 


\section{Міжнародне право}

груз был отправлен предыдущим самолетом, им сообщили о том, что он будет найден и доставлен в ближайшее время. Позже выяснилось, что их груз по ошибке снова был отправлен в Турцию и вернулся, а когда сумки в багаже были переданы им, то они видели, что большинство вещей, купленных ими в Турции, пришло в негодность. Помимо издевательств, которые они перенесли, потеря багажа и негодное состояние, в которое пришли их вещи, нанесли им тяжкий моральный вред. Приятные воспоминания о пребывании в Турции сузились в их памяти, а взамен этого нашли свое место это беззаконие. В результате, первое, что приходит на ум, когда речь идет о Турции, - эти беззаконие.

Таким образом, из-за безответственности и злого умысла сотрудников авиакомпании «Тюрк Хава Йоллары» им был нанесен серьезный материальный и моральный ущерб. Причина состоит в том, что сотрудники авиакомпании «Тюрк Хава Йоллары» незаконно закрыли двери раньше времени, зная о том, что те лица были зарегистрированы, что на их паспорт был проставлен штамп, свидетельствующий о выходе из страны, и, при этом, не предприняли никаких мер по поиску зарегистрированных пассажиров, прежде чем закрыть двери. Однако, люди, прошедшие регистрацию, имеющие свой багаж и проставленные в аэропорту штампы о выезде, находятся на территории аэропорта, и их очень легко найти по объявлению в аэропорту. Но авиакомпания «Тюрк Хава Йоллары» не только не стала их искать, не дав объявления по их поводу, но и закрыла двери раньше времени, указанного в билете, и получила прибыль (покупка новых билетов). С этой точки зрения, авиакомпания «Тюрк Хава Йоллары» должна возместить материальный и моральный ущерб, нанесенный им, чтобы предотвратить страдания других лиц от подобных действий.

В связи с пропуском истцами срока подачи иска, решением Хатаинского районного суда города Баку исковые требования не были удовлетворены.

Истцы, обжаловавшие решение в Бакинском апелляционном суде, потребовали его отмены и вынесения нового решения об удовлетворении иска, обосновав свои жалобы в соответствии с содержанием искового заявления о том, что по делу не было проведено тщательное расследование и что доказательствам не была дана надлежащая правовая оценка, что привело к незаконному заключению; они заявили, что ранее подавали апелляцию в Хатаинский районный суд и что дело не было рассмотрено из-за несоблюдения правил подачи иска.

Представитель азербайджанского офиса авиакомпании «Тюрк Хава Йоллары», присутствовавший на судебном заседании, заявил, что апелляция была необоснованной, а информация о том, что истцы подошли к выходу на посадку за 25 минут до вылета, неверна, а суду не было представлено никаких доказательств. Истцы утверждают, что, хотя они якобы подошли к выходу на посадку за 25 минут до вылета (то есть около 20:30 часов), выход на посадку уже был закрыт, и поэтому они не смогли сесть на рейс. Согласно программному обеспечению Turkish Airlines, посадка на рейс ТK336 продолжалась до 20:55 часов, то есть до этого времени выход на посадку был открыт. С другой стороны, следует отметить, что истцы не представили суду каких-либо доказательств, подтверждающих информацию в исковом заявлении о том, что истцы якобы подошли к выходу на соответствующий рейс «за 25 минут до времени, указанного в билете». Если перевозка невозможна по вине пассажиров, перевозчик освобождается от ответственности. В текущем судебном процессе истцы не смогли сесть на рейс ТК336 из-за своего неадекватного поведения. Таким образом, из прилагаемых к исковому заявлению посадочных пассажирских талонов видно, что время посадки на борт самолета началось в 19:55. То есть, истцы должны были подойти к выходу на посадку с 19:55, но не сделали этого. С другой стороны, согласно предупреждению на посадочном талоне, процедура посадки заканчивается за 15 минут до вылета. И в то же время, из искового заявления и прилагаемых к заявлению посадочных пассажирских талонов следует, что истцы обратились в суд после истечения срока подачи иска.

Решением Гражданской коллегии Бакинского апелляционного суда жалобу не удов- 
летворили, а решение Хатаинского районного суда города Баку оставлено без изменения. В решении Гражданской коллегии Бакинского апелляционного суда указывалось, что истцы не представили никаких достоверных доказательств фактов, на которых они основывали свои требования, и что суд не смог получить доказательства для проверки их доводов. Суд первой инстанции пришел к верному выводу о фактических обстоятельствах споров и взаимоотношений сторон, а доказательства, приведенные в апелляционной жалобе, не являются основанием для отмены решения. Причина состоит в том, что истечение срока исковой давности представляет собой один из важных институтов гражданского законодательства с точки зрения разрешения споров. Ссылаясь на важность этого института во многих решениях Пленума Конституционного суда, было отмечено, что правильное применение положений законодательства о сроках исковой давности имеет важность с точки зрения разрешения гражданских дел в соответствии с законом.

Срок исковой давности дисциплинирует стороны правоотношений, вынуждает их отстаивать свои права, помогает регулировать договор и финансовую дисциплину, служит для устранения неопределенности и нестабильности в гражданско-правовых отношениях, давно обошедших стороны, устраняя необходимость полагаться на доказательства, достоверность которых сложно или невозможно проверить и по отношению к которым прошли длительные сроки давности, позволяет органам правосудия разрешать споры на объективной основе.

Европейский суд по правам человека, выступая с аналогичной правовой позиции в постановлении Мирагалл Әсколано и другие против Испании от 25 января 2000 года, пришел к такому выводу, что формальные шаги, которые должны быть предприняты, и правила, регулирующие ограничения сроков, которые должны соблюдаться для подачи жалоб, носят цель обеспечения осуществления правосудия в должном порядке и в особенности в соответствии с принципом правовой определенности. Стороны судебного спора должны учитывать применение этих правил.
В постановлении Пленума Конституционного суда Азербайджанской Республики от 8 мая 2008 года относительно жалобы К.Н.Гарибовой отмечается, что «для восстановления предусмотренного законом процессуального срока уважительньли могут считаться лишь такие причинь, наличие которьгх не зависит от воли лица, обладающего процессуальнълми правами и обязанностями, которьие въхходят за предель возможностей самостоятельного их преодоления, мешают или ограничивают въполнение соответствующего действия. Признание причинъ, повлекшей истечение срока, уважительной зависит непосредственно от мнения суда. В этом контексте уважительность должна приниматься в отношении таких неопровержимых причин, стоящих на гранище указаннъх критериев, когда судебнъий акт, вълнесеннъий в связи с даннълм вопросом с соблюдением требований Гражданско-процессуального кодекса, не възъвает сомнения» (3).

В соответствии со статьей 6 Конвенции о защите прав человека и основных свобод, принятой 4 ноября 1950 года в Риме, «каждъй в случае спора о его гражданских правах и обязанностях или при предбявлении ему любого уголовного обвинения имеет право на справедливое и публичное разбирательство дела в разумнъий срок независимъим и беспристрастнылм судом, созданнъим на основании закона».

С другой стороны, надо учитывать, что согласно статье 14.2 Гражданского-процессуального кодекса Азербайджанской Республики, который был принят 28 декабря 1999 года и вступил в силу 1 сентября 2000 года, «суд рассматривает и использует только те доказательства, которьле представлень сторонами», а в соответствии со статьей 77.1 указанного Кодекса, «каждая сторона должна доказать те обстоятельства, на которье она ссъллатся как на основания свочх требований и возражений».

Стоит отметить, что в Постановлении от 26 июля 2007 года Европейский Суд по правам человека в Деле «Махмудов (Makhmudov) против Российской Федерации», повторяет: «Оценивая доказательства в рамках конвеницоннъхх процедур, он объчно руководствуется приниипом affirmanti, non neganti, incumbit probatio (бремя доказвивания лежит на том, кто делает утверждение, а не на том, что его от- 


\section{Міжнародне право}

рицает). Доказъвание может въттекать из сосуществования достаточно надежньх, четких $и$ последовательньх предположений или аналогичнъих нерушимъхх презумпиий бактов». А в деле «Гавазов против Болгарии» тот же самый Суд отметил, что «при оценке доказательств, как правило, применяются стандарты доказательств вне обоснованных сомнений».

В постановлении Пленума Конституционного суда Азербайджанской Республики от 31 мая 2006 года «О соответствии постановления Судебной коллегии по гражданским делам Верховного суда Азербайджанской Республики от 28 декабря 2004 года Конституции и законам Азербайджанской Республики в связи жалобой С.Алиевой» указывается, что «суд указав в решении установленнъге самим обстоятельства дела и доказательства, формирующие заключение, доводъ на которьие основьвался для отклонения втих или других доказательств, и законъл, которьлми руководствовался, должен обосновать его с правовой точки зрения» (4, с. 787).

Согласно пункту 1 Постановления Пленума Верховного Суда Азербайджанской Республики от 24 ноября 2005 года № 4 «О судебном решении», состоящего из 18 пунктов, так как судебное решение является заключительным актом правосудия по делам, вытекающим из гражданских и коммерческих споров, то с его принятием должна быть установлена определенность в спорных правоотношениях, обеспечено реальное восстановление нарушенных и оспариваемых прав, и охраняемых законом интересов.

Пункт 6 Постановления Пленума от 24 ноября 2005 года гласит, что в мотивировочной части решения должны быть указаны обстоятельства дела, установленные судом, доказательства, обосновывающие выводы суда, доказательства, на которые он ссылается для опровержения или принятия тех или иных доказательств, руководящие законы или иные нормативные акты. В мотивировочной части решения также необходимо указать нормы материального права, на основании которых суд пришел к выводу о спорных правоотношениях, название, статья, абзац, пункт закона или иного нормативного акта, а при необходимости также указываются Постановления Конституционного суда и Пле- нума Верховного суда по отдельным вопросам.

Считаем необходимым констатировать, что тот факт, что решения пленума Верховного суда действуют как источник законодательства о международных перевозках пассажиров и багажа по воздуху и как источник права в целом, вызывают споры на страницах юридической литературы. Согласно пункту 1 статьи 131 Конституции АР «Верховнъий Суд Азербайджанской Республики является въгсшим судебньлм органом по гражданским, уголовнъим и другим делам, отнесеннъим к производству общих и специилизированных судов; он осуществляет правосудие в кассачионном порядке; дает разъяснения по вопросам судебной практики».

На основании статьи 79 Закона Азербайджанской Республики «О судах и судьях» от 10 июня 1997 года «Пленум Верховного суда AP в соответствии со статьей 131 Конституичии Азербайджанской Республики дает судам разбяснения по вопросам судебной практики». Такие разъяснения обычно принимаются в форме постановлений Пленума Верховного Суда в порядке судебного толкования. Они основываются на обобщенных материалах.

Среди ученых-правоведов сложились два доктринальных (научных) взгляда на правовой характер постановлений Пленума Верховного Суда. Согласно позиции сторонников первого мнения, постановления пленума выступают в качестве источника права (5, с. $140 ; 9$, с. 54). Эти авторы отмечают, что постановления пленума Верховного Суда, толкующие содержание правовых норм (под правовой нормой понимается модель поведения, определяемая или санкционируемая государством, закрепленная в государственных актах, носящая обязательный характер), в процессе разъяснения смысла действующего законодательства фактически устанавливают новое правило общего характера.

Это правило отличается от нормы, выраженной в нормативном акте, является обязательным к исполнению, а также выражает волю государства. Хотя судебный орган не имеет полномочий устанавливать эту норму, некоторые из его разъяснений принимаются в качестве нормы права.

Ученые, выступающие в поддержку второй точки зрения, справедливо отмечают, 
что постановления пленума Верховного суда не могут быть признаны источником права (6, с. 57; 7, с. 61). Причина в том, что постановления пленума, главным образом, посвящены толкованию существующего законодательства, то есть уточнению и разъяснению его смысла. Они по своему правовому характеру считаются актами толкования. Постановления пленума Верховного суда предназначены для общего руководства в процессе применения права, их «судьба» связана с толкуемыми нормативными актами, зависит от этих актов. Поэтому постановления пленума имеют смысл и силу только вместе с нормативными актами. «Вместе с тем судь при разрешении конкретных споров обязанъ применять соответствуюшие нормы гражданского права лишь в истолковании, содержащемся в постановлении соответствующего судебного пленума. Поэтому участники гражданского оборота руководствуются постановлениями судебных пленумов и тогда, когда дело не доходит до суда, ито имеет чрезвъччайн важное значение для обеспечения единообразного понимания и применения гражданского законодательства» (8, с. 44).

Поскольку законодательство Азербайджанской Республики не признает постановления пленума Верховного Суда в качестве источника права, то такие постановления не выступают источником законодательства о международных перевозках пассажиров и багажа воздушным транспортом.

\section{Аитература}

1. Марченко М.Н. Теория государства и права. Москва: Проспект, 2009, 640 с.

2. Матузов Н.И., Малько А.В. Теория государства и права: Учебник. Москва: Юристь, 2004, 245 с.

3. Könül Namidar q1zı Qəribovanın şikayəti ilə əlaqədar Azərbaycan Respublikası Ali Məhkəməsi MiÜMK-1n 16 avqust 2006-c1 il tarixli qərarının Azərbaycan Respublikasının Konstitusiyasına və qanunlarına uyğunluğunun yoxlanılmasına dair Azərbaycan Respublikası Konstitusiya Məhkəməsi Plenumunun 08 may 2008-ci il tarixli Qərarı. http:// www.constcourt.gov.az/decision/155

4. Постановление Пленума Конституционного суда Азербайджанской Республики от 31 мая 2006 года «О соответствии постановления Судебной коллегии по гражданским делам Верховного суда Азербайджанской Республики от 28 декабря 2004 года Конституции и законам Азербайджанской Республики в связи жалобой С.Алиевой». Сборник постановлений Конституционного суда Азербайджанской Республики. Баку: Издательство «Нüquq әdəbiyyatı», 2008, 952 с.

5. Новицкий И.Б. Источники советского гражданского права. Москва: Юридическая литература, 1959, 157 с.

6. Красавчиков О.А. Советское гражданское право: В 2-х томах, Том 1. Москва: Высшая школа, 1985, 544 с.

7. Гражданское право: Учебник / Под редакцией Е.А.Суханова: В 2-х томах, Том 1. Москва: БЕК, 2000, 816 с.

8. Гражданское право: Учебник / Под редакцией А.П.Сергеева, Ю.К.Толстого: В 2-х томах, Том 1. Москва: Проспект, 2000, $632 \mathrm{c}$.

9. Иоффе О.С. Советское гражданское право. Москва: Юридическая литература, 1967, 494 c.

\section{Manizadeh Jamil, dissertationist of the Azerbaijan National Aviation Academy}

\section{LEGISLATIVE ACTS OF THE REPUBLIC OF AZERBAIJAN IN REGULATING RELATIONS UNDER THE CONTRACT FOR THE INTERNATIONAL AIR CARRIAGE OF PASSENGERS AND BAGGAGE}

The author considers it appropriate to amend Article 13 of the Law of the Republic of Azerbaijan "On Transport" and indicate in this article the following sentence: "Passengers can return the ticket before the start of transportation and receive back the amount paid from the transport company (carrier) carrying out the transportation, if this ticket has not been purchased. at a special rate, the rules of which do not provide for the return of amounts".

Keywords - The Republic of Azerbaijan, constitution, code, article, contract. 